\title{
Utility of bronchoscopy with bronchoalveolar lavage in diagnosing pulmonary infection in hospitalized patients with underlying malignancy
}

\author{
CW Chow MD FRCPC, A McGeer MD MPH FRCPC, G Kasupski PhD, N Senathiragah MBBS, \\ P Gallant RPT, CK Chan MD FRCPC FCCP FACP
}

\begin{abstract}
CW Chow, A McGeer, G Kasupski, N Senathiragah, P Gallant, CK Chan. Utility of bronchoscopy with bronchoalveolar lavage in diagnosing pulmonary infection in hospitalized patients with underlying malignancy. Can J Infect Dis 1998;9(2):87-93.
\end{abstract}

\begin{abstract}
Objectives: To evaluate the clinical utility of bronchoscopy with bronchoalveolar lavage (BAL) for diagnosing pulmonary infection in patients with underlying malignancy and to evaluate the impact of positive microbiology results on antimicrobial therapy.

Design: Retrospective chart review.

Setting: University-affiliated downtown teaching hospital in Toronto.

Patient population: All patients who underwent bronchoscopy with BAL from November 1990 to September 1992. Results: One hundred and thirty-nine BALs were performed, of which $82(59 \%)$ were positive for microorganisms. These 82 charts were reviewed. The main underlying diagnosis was hemotogenous malignancy (70 of 82). Primary indiction for bronchoscopy was the presence of pulmonary symptoms with or without radiographic abnormality. Common organisms identified were fungi $(\mathrm{n}=50)$, primarily Candida albicans and cytomegalovirus (CMV) (27), and 16 'usual' pathogens. Less common were herpes simplex virus (six), Pneumoncystis carinii pneumonia (PCP) (four), Legionella pneumoniae and Mycoplasma pneumoniae (one each). Eighty-seven per cent of patients were on broad spectrum antibiotics at the time of bronchoscopy. Although antiibiotic therapy was altered postbronchoscopy in 47 of the 82 cases, only 26 instances could be directly attributed to the results of BAL. Pathogens that commonly initiated specific therapy were CMV (16 of 27) and PCP (three of four). Diagnostic yield was highest in allogenic bone marrow transplant recipients (BMT). They comprised only $49 \%$ ( 40 of 82 ) of the cases but accounted for $85 \%$ (22 of 26 ) of those whose therapy was directly altered by the results of BAL. Of these 22 cases, 20 were attributed to the isolation of CMV.

Conclusions: The overall raw diagnostic yield from bronchoscopy with BAL was high at $59 \%$. Of those with positive BAL cultures, a change in antimicrobial management occurred in $32 \%$ of cases. In a patient poulation with underlying hematogenous malignancy, particularly BMT recipients, bronchoscopy with BAL is useful for a specfic diagnosis of pulmonary infection.
\end{abstract}

Key Words: Bronchoalveolar lavage, Clinical utility, Pulmonary infection

Princess Margaret Hospital, Wellesley Hospital and The Toronto Hospital, Department of Medicine, University of Toronto, Toronto, Ontario Correspondence and reprints: Dr CK Chan, The Toronto Hospital, 200 Elizabeth Street, The General Division, 10EN-220, Toronto, Ontario M5G 2C4. Telephone 416-340-3235, fax 416-971-6427, e-mail cchan@torhosp.toronto.on.ca

Received for publication January 30, 1996. Accepted August 11, 1997 


\title{
Utilité d'une bronchoscopie associée à un lavage bronchoalvéolaire pour diagnostiquer une infection pulmonaire chez des patients hospitalisés atteints d'une néoplasie sous-jacente
}

\begin{abstract}
Objectifs : Évaluer l'utilité clinique d'une bronchoscopie associée à un lavage bronchoalvéolaire (LBA) pour diagnostiquer une infection pulmonaire chez des patients hospitalisés atteints d'une néoplasie sous-jacente et mesurer l'impact de résultats microbiologiques positifs sur un traitement antimicrobien.

Modèle : Consultation rétrospective des dossiers des patients.

Contexte : Hôpital universitaire d'enseignement situé dans le centre-ville de Toronto.

Patients : Tous les patients qui avaient subi une bronchoscopie associée à un LBA de novembre 1990 à septembre 1992. Résultats : Cent trente-neuf LBA ont été pratiqués dont 82 (59\%) contenaient des micro-organismes. Ces quatre-vingtdeux dossiers ont été passés en revue. Le diagnostic principal sous-jacent était une néoplasie hématologique (70 sur 82). La principale indication pour une bronchoscopie était la présence de symptômes pulmonaires avec ou sans anomalie radiographique. Les organismes couramment identifiés étaient des champignons $(n=50)$, principalement Candida albicans, le cytomégalovirus (CMV) (27), et 16 organismes pathogènes «habituels». Étaient moins fréquents : le virus de l'herpès (six), la pneumonie à Pneumocistis carinii (PPC) (quatre), la pneumonie à Legionella pneumonia et la pneumonie à Mycoplasma pneumonia (un cas de chaque). Quatre-vingt-sept pour cent des patients recevaient des antibiotiques à large spectre au moment de la bronchoscopie. Bien que le traitement antibiotique ait été modifié après la bronchoscopie dans 47 des 82 cas, ce changement de traitement n'était directement attribuable aux résultats du LBA que dans 26 cas. Les pathogènes souvent à l'origine d'une thérapie spécifique étaient le CMV (seize sur vingt-sept) et la pneumonie à Pneumocistis carinii (trois sur quatre). L'efficacité diagnostique de l'examen était plus élevée chez les patients qui avaient subi une greffe de moelle osseuse allogène. Ce groupe comprenait seulement $49 \%$ des cas (40 sur 82) mais représentait $85 \%$ (22 sur 26) de ceux dont la modification du traitement antibiotique était directement liée aux résultats du LBA. Dans 20 cas sur 22, l'isolement du CMV était à l'origine de la modification du traitement.

Conclusions : L'efficacité diagnostique brute et globale d'une bronchoscopie associée à un LBA était élevée à $59 \%$. En outre, un changement de traitement antimicrobien était survenu dans $32 \%$ des cas avec des cultures du LBA positives. Dans une population de patients atteints d'une néoplasie hématologique, surtout chez ceux qui ont subi une greffe de moelle osseuse, la bronchoscopie associée à un LBA est utile pour préciser le diagnostic microbiologique d'une infection pulmonaire.
\end{abstract}

$\mathrm{P}$ ulmonary complications occur commonly in patients with underlying immunosuppression and pose a challenging diagnostic problem. Fever, cough, dyspnea and/or new pulmonary infiltrates on chest roentgenogram in this patient population herald the onset of illnesses of many diverse etiologies. Illnesses include recurrence of tumour, pulmonary infection, adverse reaction from chemotherapy or radiation therapy, cardiogenic or noncardiogenic pulmonary edema and, in patients with allogeneic bone marrow transplants (BMT), graft-versushost disease. Previous reports have found that over $50 \%$ of these symptoms are infectious in etiology $(1,2)$. In the majority of cases, the pathogens implicated were opportunistic organisms such as cytomegalovirus (CMV) and Pneumocystis carinii pneumonia (PCP) (1-3), which if left untreated are associated with significant and high mortality and morbidity. Early diagnosis is important because specific therapy is now available for many infectious complications including PCP and CMV infection. Recent developments of specific monoclonal antibodies and DNA hybridization techniques now permit early and accurate detection of PCP and CMV (4-8).

Recent studies have shown that early treatment of CMV pneumonitis in allogeneic BMT patients improves patient outcome, which had previously been associated with mortality rates of over $80 \%(5,9,10)$. It is now well established that early treatment of PCP significantly increases survival, and the decreasing incidence of $\mathrm{PCP}$ in BMT patients in the published literature is likely a reflection of the increasing use of trimethoprim/sulfamethoxasole (TMP/SMX) prophylaxis in this population.

Bronchoscopy with bronchoalveolar lavage (BAL), a tech- nique developed in the early 1970s, is relatively noninvasive and allows visualization of the airways and sampling of alveolar cells and fluid (11-15). The complication rate is low, occurring in less than $5 \%$ of all patients undergoing the procedure (13). Complications consist of transient fever, pneumonitis and transient hypoxemia. Reports of this technique used in patients supported by mechanical ventilation and in patients with underlying malignancy who have increased incidence of hypoxemia, thrombocytopenia and coagulapathy have proven bronchoscopy with BAL to be safe and useful $(2,13,16)$. In an immunocompromised population, the diagnostic yield of bronchoscopy with BAL has been reported to vary from $32 \%$ to $66 \%(2,3,17-19)$.

It is the policy at Princess Margaret and Wellesley Hospital, Toronto, Ontario to pursue aggressively a diagnosis in patients with underlying malignancy and new pulmonary symptoms. As such, early bronchoscopy with BAL is the rule. We undertook this quality assurance study to assess the clinical efficacy and utility of this diagnostic procedure over a 22 -month period in identification of pulmonary infection. We were primarily interested in assessing the impact of positive microbiological findings on BAL on antimicrobial therapy.

\section{PATIENTS AND METHODS}

Patient selection: A logbook of all patients who underwent bronchoscopy at the Princess Margaret Hospital from November 1990 onwards was kept in the Respiratory Therapy Department. All patients included in the log from November 1989 to September 1992 (a 22-month period) were included. Only those patients who had bronchoscopy performed without any 
TABLE 1

Underlying malignancies in patients undergoing bronchoscopy with bronchoalveolar lavage

\begin{tabular}{lc}
\hline Diagnosis & Number of patients \\
\hline Leukemia & 48 \\
Chronic myelogenous & 23 \\
$\quad$ leukemia & 18 \\
AML & 7 \\
Acute lymphocyte leukemia & 9 \\
Lymphoma & 6 \\
Non-Hodgkin's lymphoma & 3 \\
Hodgkin's lymphoma & 4 \\
Multiple myeloma & 4 \\
Aplastic anemia & 2 \\
Red cell aplasia & 1 \\
Myelofibrosis & 1 \\
AML + seminoma & 1 \\
AML + myelofibrosis & 12 \\
Solid tumours* &
\end{tabular}

*Solid tumours: breast $(n=2)$, lung and esophagus $(n=1)$, cervix $(n=1)$, prostate $(n=1)$, nasopharynx $(n=2)$, anal $(n=1)$, bladder $(n=1)$, central nervous system $(n=2)$ and mesothelioma $(n=1)$. AML Acute myelogenous leukemia

respiratory samples for microbiological investigation were excluded from the analysis. The charts of only those patients whose BAL yielded positive microbiology results to assess how BAL altered antimicrobial therapy were reviewed.

Setting: Princess Margaret Hospital is a downtown, university-affiliated teaching hospital and is the major oncology referral centre in southern Ontario. All patients were in-patients at the time of bronchoscopy. All had underlying malignancy.

Bronchoscopy, bronchoalveolar lavage and specimen handling procedure: Bronchoscopies were routinely performed within $24 \mathrm{~h}$ of the initial consultation and within $48 \mathrm{~h}$ of development of new symptoms. Bronchoscopy was completed in the standard manner via the orotracheal route. No premedications were given. Patients were anesthetized with topical xylocaine and given intravenous sedation. Bronchoscopies were completed by one of four pulmonary consultants with the same respiratory technician and a senior medical resident or pulmonary fellow. BAL was performed using sterile normal saline at room temperature using a total volume of $100 \mathrm{~mL}$ in $20 \mathrm{~mL}$ aliquots. Samples were collected in sterile containers separate from those used for routine suctioning. BAL was performed in the lingula and right middle lobe, unless a focal finding on the chest roentgenogram dictated otherwise.

At the time of bronchoscopy, all BAL specimens were handled as priority specimens and were delivered immediately to the microbiology and virology laboratories. All specimens were processed by using Gram stain, Ziel-Nielson stain, routine bacterial and fungal cultures, legionella direct fluorescent immune fluorescence stain, legionella cultures (completed at the Ontario Provincial Health Laboratories, Etobicoke, Ontario), mycobacterial direct fluorescent antigen stain and mycobacterial cultures (performed at the Ontario Provincial
TABLE 2

Immunosuppressive factors at time of bronchoscopy

\begin{tabular}{lc}
\hline Immunosuppressive factor & Number of patients \\
\hline Recent chemotherapy & 62 \\
Allogeneic bone marrow transplant & 40 \\
recipient* & \\
Neutropenic $^{\dagger}$ & 40 \\
\hline
\end{tabular}

*Twenty of the allogeneic bone marrow transplant recipients were also neutropenic and had recent chemotherapy. ${ }^{\dagger}$ All but four patients had recent chemotherapy; of the four, three had underlying acute myelogenous leukemia, one had prostate cancer and none were allogeneic bone marrow transplant recipients

Health Laboratories). All but eight samples were also tested for herpes simplex virus (HSV) and CMV by direct immunofluorescence stain and viral cultures, as well as for PCP by direct immune fluorescence stains. Presence of CMV was also detected by the $16 \mathrm{~h}$ shell vial technique.

Data collection: All data were extracted manually in a retrospective manner and subsequently entered into a computer database programme (Microsoft Access, Microsoft, Washington). A review of the results of the BAL samples as reported in the final microbiology and virology reports was completed for all patients included in the study. In those who had at least one positive result in any of the reports, a retrospective chart review was completed. Data obtained included age, sex, underlying diagnosis or diagnoses, whether patient was a allogeneic BMT recipient, reasons for bronchoscopy (cough, fever, dyspnea, hypoxemia, abnormal roentgenogram, etc), roentgenogram findings, presence of neutropenia, recent chemotherapy, and complications encountered postbronchoscopy (in particular the need for intubation and intensive care unit admission). All organisms isolated from the BAL sample were recorded as were the antibiotics used before and after bronchoscopy.

If a new antimicrobial was started after results of the BAL became available and the antimicrobial agent was specific for the organism identified (eg, ganciclovir for CMV, high dose TMP/SMX for PCP), this was considered good evidence that BAL directly influenced therapy. If antimicrobials were initiated immediately after bronchoscopy or if the changes did not have any correlation with the BAL finding, this alteration was not considered to result from the procedure.

\section{RESULTS}

A total of 151 bronchoscopies were completed during this period of time. Twelve were done for purpose of airway inspection and were excluded from the study. The remaining 139 procedures performed in 104 patients form the basis of this review. Eighty-two of the 139 procedures (59\%) had at least one organism identified, and the charts of these patients were reviewed.

The majority of patients had an underlying hematogenous malignancy (85\%). Only 12 of 82 cases had an underlying solid tumour (Table 1). Forty patients were neutropenic, and 62 had received recent chemotherapy (Table 2). Forty were allogeneic BMT recipients. 
TABLE 3

Reasons for bronchoscopy

\begin{tabular}{lc}
\hline Reason & $\begin{array}{c}\text { Number } \\
\text { of patients }\end{array}$ \\
\hline $\begin{array}{l}\text { Symptoms } \\
\text { Cough/fever/dyspnea }+ \text { abnormal } \\
\text { roentgenogram }\end{array}$ & 52 \\
$\begin{array}{l}\text { Cough/fever/dyspnea + normal } \\
\text { roentgenogram }\end{array}$ & 2 \\
Abnormal roentgenogram alone & \\
Rule out pulmonary metastasis & 5 \\
Rule out CMV pneumonitis & 6 \\
Rule out Pneumocystis carinii pneumonia & 10 \\
Assess CMV shedding following treatment & 1 \\
\hline
\end{tabular}

CMV Cytomegalovirus

\section{TABLE 4}

Organisms identified in bronchoalveolar lavage in patients with underlying malignancy

\begin{tabular}{lc}
\hline Organism & All patients \\
\hline Fungus & $50(41)$ \\
Candida albicans & 23 \\
Aspergillus fumigatus & 7 \\
Cryptococcus neoformans & 1 \\
Bacteria & $16(15)$ \\
Haemophilua influenzae & 3 \\
Pseudomonas aeruginosa & 3 \\
Streptococcal species & 2 \\
Staphylococcal species & 2 \\
Haemophilus parainfluenzae & 1 \\
Other Gram-negative organisms & 3 \\
Legionella pneumophila & 1 \\
Mycoplasma pneumoniae & 1 \\
Virus & $33(29)$ \\
Cytomegalovirus* & 27 \\
Herpes simplex virus & 6 \\
Pneumocystis carinii pneumonia & 4 \\
\hline
\end{tabular}

*Two patients had cytomegalovirus and herpes simplex virus, one had Pneumocystis carinii pneumonia plus cytomegalovirus. () indicates patients who were already on antibiotics at time of bronchoscopy

In the majority of cases, reasons for bronchoscopy were based on the presence of new pulmonary symptoms and/or abnormal chest roentgenogram. Bronchoscopy in six cases was completed to rule out presence of pulmonary metastases and six to assess CMV shedding for surveillance purposes or to assess efficacy of CMV therapy (Table 3).

Complications of bronchoscopy were rare. Of the 82 cases, only two patients required intubation, one as a preventative measure for airway protection during the procedure; the second patient remained intubated for $24 \mathrm{~h}$ postbronchoscopy. No patient died as a result of the bronchoscopy.

Fifty-nine per cent of all procedures performed during this period of time (82 of 139) yielded a positive result on exami-
TABLE 5

Organisms implicated in antimicrobial therapy changes postbronchoscopy and bronchoalveolar lavage

\begin{tabular}{lccc}
\hline $\begin{array}{l}\text { Organism(s) } \\
\text { implicated }\end{array}$ & $\begin{array}{c}\text { BMT } \\
\text { patients }\end{array}$ & $\begin{array}{c}\text { Non-BMT } \\
\text { patients }\end{array}$ & $\begin{array}{c}\text { Number of } \\
\text { patients }\end{array}$ \\
\hline $\begin{array}{l}\text { Virus } \\
\text { Cytomegalovirus }\end{array}$ & 15 & 1 & 16 \\
Bacteria* & 3 & 1 & 4 \\
$\begin{array}{l}\text { Fungit } \\
\text { Pneumocystis carinii }\end{array}$ & 2 & 1 & 3 \\
pneumonia & 1 & 3 \\
*Bacteria isoloated were Staphylococcus pneumoniae (1), Pseudomonas \\
aeruginosa (1), Haemophilus influenzae (1) and Legionella pneumophila \\
(1). 'Fungi isolated were Aspergillus fumigatus (2) and Candida albicans \\
(1). BMT Bone marrow transplant
\end{tabular}

TABLE 6

Results of bronchoalveolar lavage in $\mathbf{4 0}$ bone marrow transplant recipients who underwent bronchoscopy

\begin{tabular}{|c|c|c|}
\hline Organism(s) identified & $\begin{array}{l}\text { Specific therapy } \\
\text { started }(n=21)\end{array}$ & $\begin{array}{l}\text { Deaths } \\
(n=8)\end{array}$ \\
\hline Cytomegalovirus $(n=20)$ & Ganciclovir $(n=15)^{*}$ & 3 \\
\hline \multicolumn{3}{|l|}{ Bacteria $(n=9)$} \\
\hline $\begin{array}{l}\text { Gram-negative bacilli } \\
(n=7)\end{array}$ & $\begin{array}{l}\text { Ceftazidine } \pm \\
\text { ciprofloxacin }(n=2)\end{array}$ & 2 \\
\hline $\begin{array}{l}\text { Streptococcus } \\
\text { pneumoniae }(n=1)\end{array}$ & Penicillin $(n=1)$ & 0 \\
\hline $\begin{array}{l}\text { Mycoplasma } \\
\text { pneumoniae }(n=1)\end{array}$ & Nil & 0 \\
\hline Fungi $(n=22)$ & Amphotericin $(n=2)$ & 1 \\
\hline $\begin{array}{r}\text { Pneumocystis carinii } \\
\text { pneumonia }(n=2)\end{array}$ & $\mathrm{TMP} / \mathrm{SMX}(\mathrm{n}=2)$ & 1 \\
\hline
\end{tabular}

nation of the BAL fluid for microorganisms. Of the organisms isolated, the most common were CMV, Candida albicans, Aspergillus fumigatus, HSV and PCP. Not surprisingly, the recovery of common bacterial pathogens is low in this setting (Table 4).

Among the 71 patients ( $87 \%$ ) who were on antibiotics at the time of bronchoscopy, the most common organisms isolated were fungi (50) and viruses (CMV 27, HSV 6). Not unexpectedly, the identification of bacteria in this group was low (Table 4).

In 47 of 82 cases, antimicrobial therapy was different postbronchoscopy. However, only 26 changes in treatment could be directly attributable to the BAL findings (Table 5). These included the 16 patients who were started on ganciclovir with or without hyperimmune gamma globulin for CMV and three who were started on high dose TMP/SMX for PCP. In three patients, intravenous amphotericin was initiated when BAL was positive for A fumigatus $(\mathrm{n}=2)$ and $C$ albicans $(\mathrm{n}=1)$. In patients with positive bacterial cultures, the authors were able to attribute change in specific antimicrobial therapy to the or- 
Bronchscopy and bronchoalveolar lavage in patients with malignancy

TABLE 7

Nonbone marrow transplant recipients whose antimicrobial therapy was changed postbronchoalveolar lavage $(\mathrm{n}=4)$

\begin{tabular}{lcccc}
\hline Organism isolated & $\begin{array}{c}\text { Antimicrobial agent } \\
\text { started }\end{array}$ & $\begin{array}{c}\text { Underlying } \\
\text { diagnosis }\end{array}$ & Neutropenia & $\begin{array}{c}\text { Prior } \\
\text { antibiotics }\end{array}$ \\
Ontcome
\end{tabular}

TMP/SMX Trimethoprim/sulfamethoxazole

ganism identified from BAL specimen in four cases. The pathogens identified in these four patients were Streptococcus pneumoniae, Pseudomonas aeruginosa, Haemophilus influenzae and Legionella pneumophila, respectively. Four other patients with positive fungal cultures were also started on antifungal therapy post-BAL. However, it was unclear whether initiation of therapy was due to results of the procedure or as part of the regiment for treatment of febrile neutropenia. It is the routine to start antifungal therapy on day 3 in cases of unresolved febrile neutropenia at this institution.

All of the 40 BMT recipients who underwent bronchoscopy were culture positive on examination of BAL fluid despite the fact that 38 of 40 patients were already on antibiotics at time of investigation. Organisms isolated in this patient subgroup include fungi ( $\mathrm{n}=22$, predominantly $C$ albicans and $A$ fumigatus), CMV ( $\mathrm{n}=22)$, bacteria (seven Gram-negative bacilli, one $S$ pneumoniae, one Mycoplasma pneumoniae) and PCP $(\mathrm{n}=2)$. BAL cultures had a direct impact on antimicrobial therapy in 22 of the 40 patients $(55 \%)$ (Tables 5,6$)$. Fifteen of the 20 patients positive for CMV were started on ganciclovir with or without hyperimmune gamma globulins. The remaining five patients positive for CMV were already on ganciclovir at time of bronchoscopy. Bronchoscopy in these patients was completed to investigate viral shedding after initiation of ganciclovir treatment for CMV pneumonitis. Three of the nine patients with positive bacterial cultures, two of 22 with positive fungal cultures and two of two patients positive for PCP were started on specific antimicrobial therapy (Table 7). Thus, in BMT patients suspected of having a pulmonary infection, bronchoscopy with BAL helped with an early diagnosis and changed therapy in $55 \%$ of cases. Of these, $68 \%$ (15 of 22 ) were postive for CMV.

of the 42 non-BMT patients with underlying malignancy, bronchoscopy with BAL directly influenced antimicrobial therapy in only four cases (9.5\%) (Table 5). All four were on antibiotics at time of investigation. Two patients with underlying red cell aplasia were positive for PCP and $P$ aeruginosa, respectively. The patient with acute myelogenous leukemia was positive for $C$ albicans, and the remaining patient, who had underlying astrocytoma, was positive for CMV. Two of the four patients survived and were discharged from hospital. The two patients with $C$ albicans and $P$ aeruginosa, respectively, died during their hospital stay (Table 8).

Fifteen patients of the 82 patients with positive BAL cultures $(18 \%)$ died during hospitalization. Of these, eight were
TABLE 8

Characteristics of patients who died during hospital stay

\begin{tabular}{lcc}
\hline Underlying diagnosis $(\mathbf{n = 1 5})$ & $\begin{array}{c}\text { BMT } \\
(\mathbf{n = 8})\end{array}$ & $\begin{array}{c}\text { Non-BMT } \\
(\mathbf{n}=7)\end{array}$ \\
\hline Chronic myelogenous leukemia & 4 & 1 \\
Acute myelogenous leukemia & 0 & $4^{*}$ \\
Multiple myeloma & 2 & 0 \\
Red cell aplasia & 0 & 1 \\
Hodgkin's lymphoma & 0 & 1 \\
Myelofibrosis & 1 & 0 \\
Aplastic anemia & 1 & 0 \\
Neutropenia & 4 & 5 \\
Microbiology of bronchoavleolar lavage & \\
Candida albicans & 5 & $1^{\dagger}$ \\
Aspergillus fumigatus & $1^{\dagger}$ & 2 \\
Herpes simplex virus & 0 & 3 \\
Cytomegalovirus & $2^{\dagger}$ & 0 \\
Pneumocystis carinii pneumonia & $1^{\dagger}$ & 0 \\
Mycoplasma pneumoniae & 0 & 1 \\
Haemophilus influenzae & $1^{\dagger}$ & 0 \\
Pseudomonas aeruginosa & 0 & $1^{\dagger}$ \\
\hline
\end{tabular}

*One also had myelofibrosis and another also had seminoma. ${ }^{\dagger}$ Specific antimicrobial agents were started postbronchoscopy with bronchoscopy with bronchoalveolar lavage. BMT Bone marrow transplant

BMT recipients and seven non-BMT recipients. Nine were febrile and neutropenic patients. Antimicrobial therapy was directly altered by BAL results in seven patients (46.7\%). Four of these patients were febrile neutropenic. Five of the seven were $\mathrm{BMT}$ recipients in whom specific therapy was started for CMV $(\mathrm{n}=2)$, A fumigatus $(\mathrm{n}=1), \operatorname{PCP}(\mathrm{n}=1)$ and H influenzae $(\mathrm{n}=1)$ (Table 8). The two non-BMT recipients who received specific antimicrobial therapy but later died were described above. of the seven patients who died despite an infectious diagnosis being made on BAL and initiation of appropriate therapy, four were febrile neutropenic.

In eight of the 15 patients who died, bronchoscopy with BAL did not make an impact on the antimicrobial therapy given. All had an underlying hematogenous malignancy (chronic myelogenous leukemia, $n=3$; acute myelogenous leukemia, $n=3$; Hodgkin's lymphoma, $n=1$; multiple myeloma, $\mathrm{n}=1$ ). All were on antibiotics at time of investigation. Five patients were febrile neutropenic, of which three were BMT re- 
cipients. In all but two cases, the organisms isolated from BAL were fungi ( $C$ albicans, $\mathrm{n}=4$; $A$ fumigatus, $\mathrm{n}=1$; penicillium species, $n=1)$. One patient was completely culture negative. The final patient had HSV (Table 8).

In a patient population of underlying malignancy and suspected pulmonary infection, the overall yield of bronchoscopy was 59\% (82 of 139). The overall impact of bronchoscopy with BAL, as assessed by a change in antimicrobial therapy that could be directly linked to BAL culture results, was $19 \%$. However, subanalysis showed that bronchoscopy with BAL had a much higher clinical impact in allogeneic BMT recipients. BMT patients compromise $49 \%$ (40 of 82 ) of those with positive BAL but 22 of 26 patients ( $85 \%$ ) where BAL cultures directly altered antimicrobial therapy. A diagnosis of pulmonary infection was made in $55 \%$ ( 22 of 40 ) of BMT patients examined. In the subgroup of non-BMT patients with underlying malignancy, the impact of bronchoscopy with BAL on antimicrobial therapy was significantly less, directing a change in treatment strategy in only four of the $42(9.5 \%)$ cases. In patients with underlying solid tumours, bronchoscopy with BAL also had a small impact in the diagnosis of pulmonary infections, directing therapy in only two of $12(16.7 \%)$ cases.

\section{DISCUSSION}

The incidence of pulmonary infection in patients with underlying malignancy and new pulmonary symptoms is high $(1,2)$. The development of effective new antimicrobial agents, particularly antiviral agents, underscores the need for quick and noninvasive means of making a specific diagnosis. Bronchoscopy with BAL is a quick and noninvasive investigation with few complications. The development of new techniques in the microbiology laboratory permits identification of not only common bacterial organisms but also the rapid identification of common and virulent opportunistic pathogens, such as CMV and PCP.

Analysis of 139 bronchoscopies with BAL performed over a 22-month period in an ill in-patient population with underlying malignancy reveals that the procedure is safe and well tolerated. Diagnostic yield is high at $59 \%$, with $19 \%$ of all procedures resulting in a direct change in antimicrobial therapy. For those with underlying hematogenous malignancy, the diagnostic yield is higher, and in the subgroup of BMT patients, the yield in highest. In BMT patients, a specific pulmonary diagnosis was made and resulted in change in antimicrobial therapy in $55 \%$ of cases. These results suggest that bronchoscopy with BAL is an important tool for diagnosing pulmonary infections in the BMT population.

This is the first study to assess the impact value of a positive microbiological finding from BAL on antimicrobial therapy in this patient population. Our overall raw diagnostic yield is comparable with those previously reported $(2,3,17$ 19). The variation in the previously reported diagnostic yields (from $32 \%$ to $66 \%$ ) can be attributed to several factors. Studies that included a large proportion of patients infected by human immunodeficiency virus or those that included noninfectious diagnoses such as pulmonary hemorrhage increase the overall diagnostic yield. Similarly, in the study that reported the highest diagnostic yield of $66 \%$ (2), patients with no final diagnosis made were excluded in the denominator.

The most common organisms isolated in our study were viral agents (CMV, HSV), fungi (PCP, C albicans) and atypical organisms (L pneumophila). These are organisms for which specific therapy exists or for which effective therapy exists but with significant adverse side effects. Therefore, early identification of these pathogens is important because therapy for eradciation of these organisms is usually not initiated unless the organism is identified.

Many of the fungi isolated in this study were $C$ albicans. The clinical implications of this are unclear because many of these patients were colonized and specific therapy would only have been initiated if the laboratory findings correlated with a compatible clinical picture. The fact that most of these patients were not started on antifungal therapy suggests that the finding was not clinically significant. Twenty-three cases had isolates of $C$ albicans from BAL but in only one of 23 patients was amphotericin started. $C$ albicans was in fact the most common contaminant isolated from BAL of patients with underlying malignancy.

Another common fungal contaminant was Afumigatus. Of the nine cases in which it was identified, only two patients were started on antifungal therapy after organism isolation. Similarly, bacterial cultures were also often deemed to be contaminants with specific antimicrobial therapy begun in only four of 16 culture positive cases (Tables 4,5 ). This is not surprising because the majority of these immunocompromised patients are usually started on broad-spectrum antibiotics empirically at any indication of infection.

The clinical course of the 82 patients suggests that designation of $C$ albicans, $A$ fumigatus and some bacterial strains as contaminants in this setting is appropriate. Fungal strains were isolated from 50 patients. Seven of 47 patients (15\%) who did not receive antifungal therapy and two-thirds of patients $(67 \%)$ who did receive antifungal therapy died. Of the 14 patients who had positive bacterial cultures on BAL, three died (21\%). Two were started on broad spectrum antibiotics for Gram-negative bacilli, and the third patient was on erythromycin for M pneumoniae at time of bronchoscopy. It is likely that in most of these cases, the patients died with rather than because of a pulmonary infection.

Demonstration of fungi and typical bacteria in BAL sample is not helpful in clinical management of this ill patient population because colonization of the upper airways is common and clinical correlation is required. Moreover, less invasive means of identifying these organisms, such as blood cultures, are available if fungal or bacterial infections are suspected. However, in suspected viral pneumonia, bronchoscopy with BAL was found to be very useful in confirming a diagnosis. The highest yield from bronchoscopy with BAL was found in the BMT recipient population where $55 \%$ of the procedures resulted in a change of antimicrobial therapy. CMV was isolated in 20 cases (50\%). In 15 of the 20 cases (75\%), specific therapy was initiated. In the remaining five cases, the patients were already on appropriate therapy, which was continued.

Indeed, our results suggest that in a subpopulation of BMT 
patients, bronchoscopy with BAL is a very useful tool in diagnosing pulmonary infections. This is particularly true in cases where CMV pneumonitis is suspected. The incidence of CMV infection in this population is high. Bronchoscopy with BAL provided a rapid and relatively noninvasive means of making a diagnosis, especially compared with the gold standard of open lung biopsy. Recent evidence suggesting that early treatment of CMV pneumonitis may favourably improve patient outcome underscores the importance of an early diagnosis $(9,10)$.

Because of the retrospective nature of our study, there are obvious limitations. Many of the organisms isolated are likely colonizers and not pathogens. Unfortunately, this is not a problem that a retrospective study can control. We can only surmise that the change in antimicrobial therapy was a result

\section{REFERENCES}

1. Tenholder MF, Hooper RG. Pulmonary infiltrates in leukemia. Chest 1980;78:468-73.

2. Stover DE, Zaman MB, Hajdu SI, Lange M, Gold J, Armstrong D. Bronchoalveolar lavage in the diagnosis of diffuse pulmonary infiltrates in the immunosuppressed host. Ann Intern Med 1984;101:1-7.

3. Springmeyer SC, Hackman RC, Holle R, et al. Use of bronchoalveolar lavage to diagnose acute diffuse pneumonia in the immunocompromised host. J Infect Dis 1986;154:604-10.

4. Young JA, Hopkin JM, Cuthbertson WP. Pulmonary infiltrates in immunocompromised patients: Diagnosis by cytological examination of bronchoalveolar lavage fluid. J Clin Pathol 1984;37:390-7.

5. Erice A. Diagnosis of cytomegalovirus pneumonitis after bone marrow transplantation: Is PCR the answer? Am J Clin Pathol 1991;96:564-7.

6. Burgart LJ, Heller MJ, Reznicek MJ, Greiner TC, Teneyck CJ, Robinson RA. Cytomegalovirus detection in bone marrow transplant patients with idiopathic pneumonitis. Am J Clin Pathol 1991;96:572-6.

7. Crawford SW, Bowden RA, Hackman RC, Gleaves CA, Meyers JD, Clark JG. Rapid detection of cytomegalovirus pulmonary infection by bronchoalveolar lavage and centrifugation culture. Ann Intern Med 1988;108:180-5.

8. Paradis IL, Grgurich WF, Dummer JS, Dekker A, Dauber JH. Rapid detection of cytomegalovirus pneumonia from lung lavage cells. Am Rev Respir Dis 1988;138:697-702.

9. Erice A, Jordan C, Chace BA, Fletcher C, Chinnock BJ, Balfour HH. Ganciclovir treatment of cytomegalovirus disease in transplant recipients and other immunocompromised hosts. JAMA $1987 ; 257: 3082-7$ of the procedure. Although we can be quite confident in most cases (ganciclovir for CMV, high dose TMP/SMX for PCP, erythromycin for legionella), we can only be relatively certain in other cases where the organisms isolated are not always pathogenic.

In this select but ill population, diagnostic yield from bronchoscopy with BAL is high. Given the low complication rate and relatively high yield for organisms that are not covered by broad spectrum antibiotics, bronchoscopy with BAL is a useful tool for making a specific diagnosis of pulmonary infection in immunocompromised patients. Diagnostic yield of bronchoscopy with BAL for viral pneumonia is particularly high in this population. This is particularly true in allogeneic BMT patients where early recognition and, therefore, earlier treatment of CMV infection may improve morbidity and mortality.

10. Emanuel D, Cunningham I, Jules-Elysee K, et al. Cytomegalovirus pneumonia after bone marrow transplantation successfully treated with the combination of ganciclovir and high-dose intravenous immune globulin. Ann Intern Med 1988;109:777-82.

11. Costabel U, Bross KJ, Matthys H. Diagnosis by bronchoalveolar lavage of cause of pulmonary infiltrates in haematological malignancies. Br Med J 1985;290:1041.

12. Sokolowski JW, Burgher LW, Jones FL, Patterson JR, Selecki PA. Guidelines for fibreoptic bronchoscopy in adults. Am Rev Respir Dis $1987 ; 136: 1066$

13. Olopade CO, Prakash UBS. Bronchoscopy in the critical-care unit. Mayo Clin Proc 1989;64:1255-63.

14. Reynolds H. Bronchoaleolar lavage. Am Rev Respir Dis 1987;135:250-63.

15. Crystal RG, Reynolds HY, Kalica AR. Bronchoalveolar lavage: The report on an international conference. Chest 1986;90:122-31.

16. Martin WJ II, Smith TF, Brutinel WM, Cockerill FR III, Douglas WM. Role of bronchoalveolar lavage in the assessment of opportunistic pulmonary infections: utility and complications. Mayo Clin Proc 1987;62:549-57.

17. Pisani RJ, Wright AJ. Clinical utility of bronchoalveolar lavage in immunocompromised hosts. Mayo Clin Proc 1992;67:221-7.

18. Abramson MJ, Stone CA, Holmes PW, Tai EH. The role of bronchoalveolar lavage in the diagnosis of suspected opportunistic pneumonia. Aust NZ J Med 1987;17:407-12.

19. Cordonnier C, Bernaudin J-F, Fleury J, et al. Diagnostic yield of bronchoalveolar lavage in pneumonitis occurring after allogeneic bone marrow transplant. Am Rev Respir Dis $1985 ; 132: 1118-23$ 


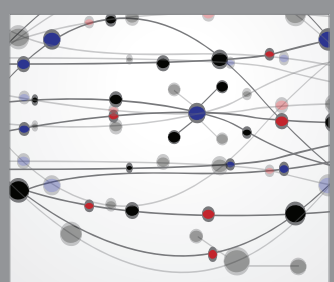

The Scientific World Journal
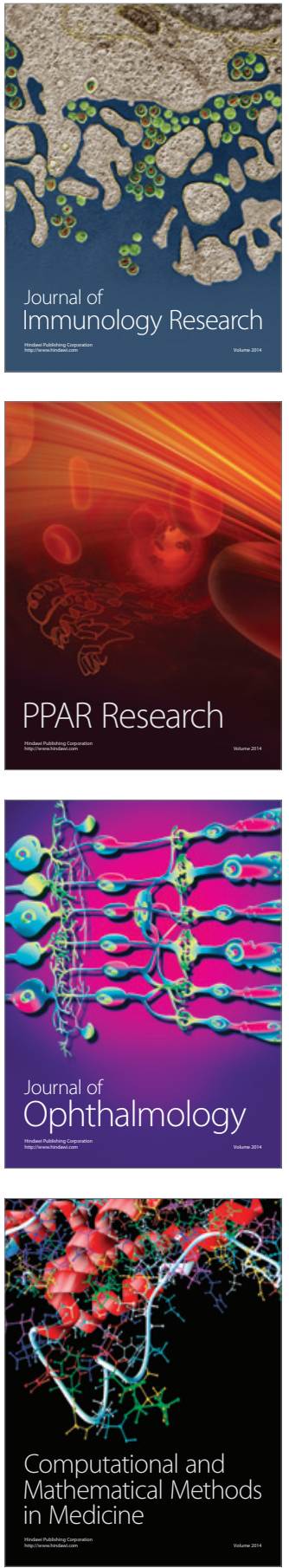

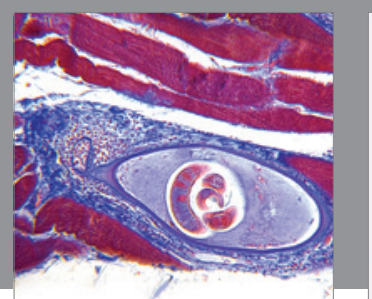

Gastroenterology Research and Practice

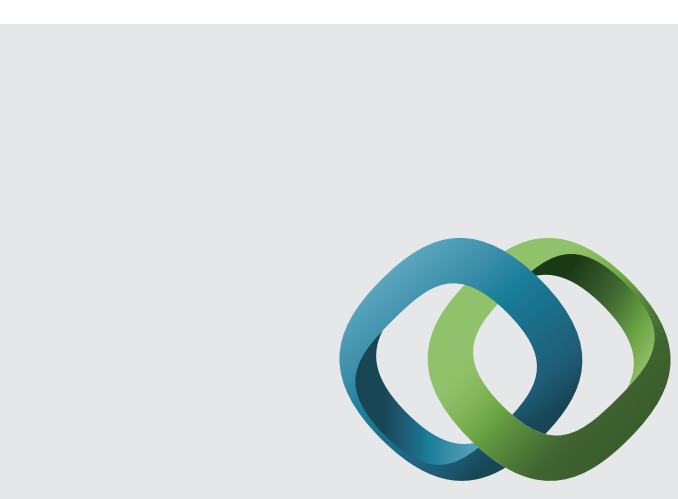

\section{Hindawi}

Submit your manuscripts at

http://www.hindawi.com
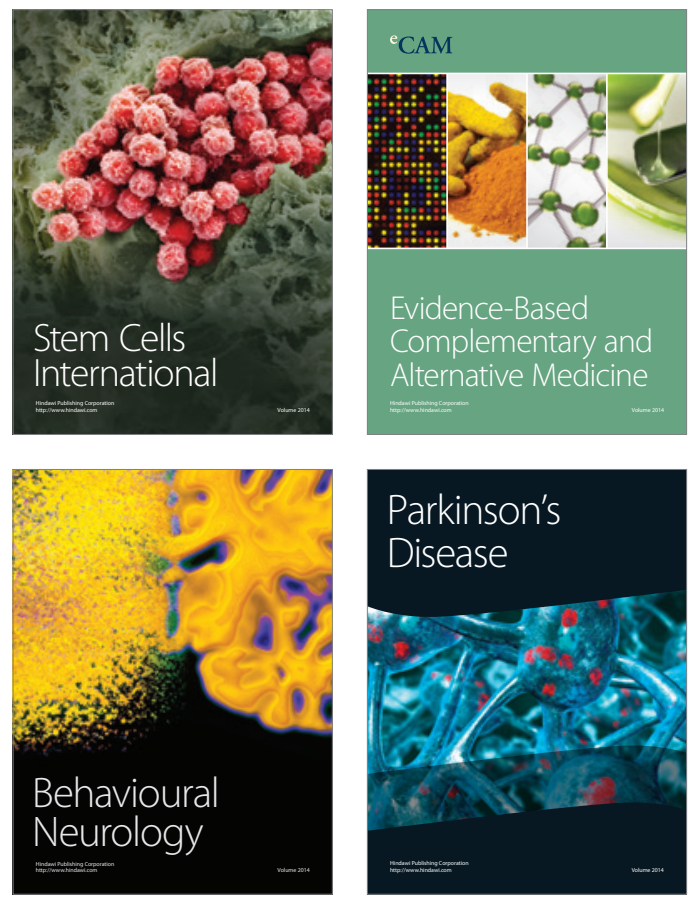
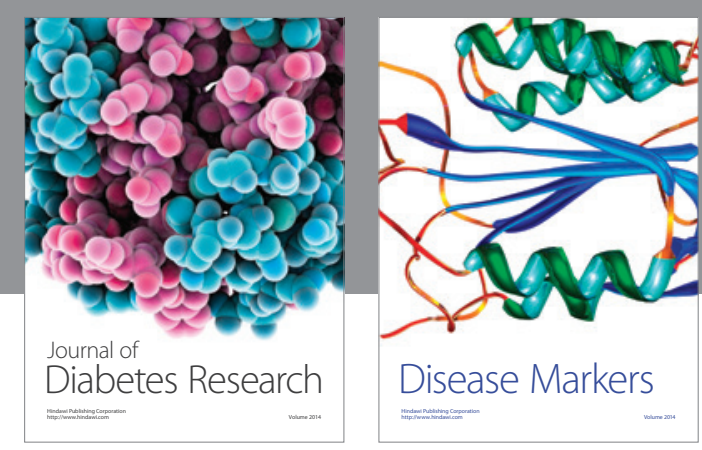

Disease Markers
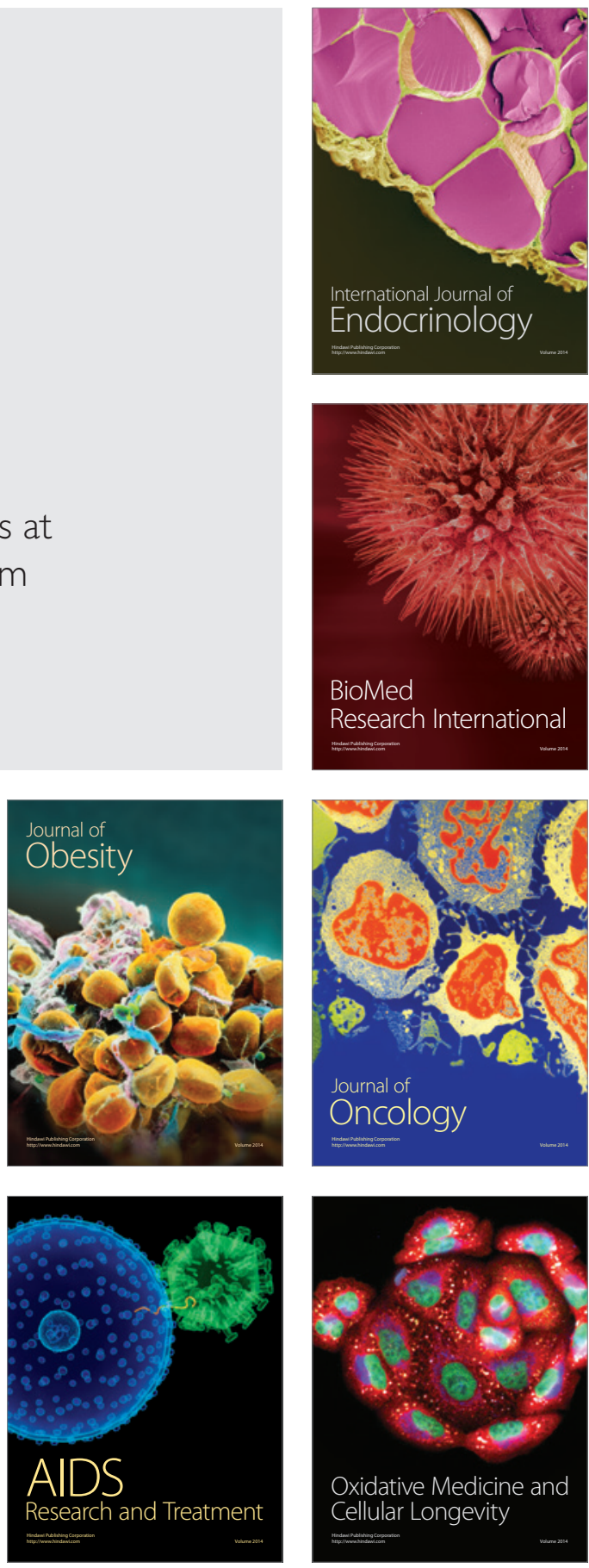